\title{
Revitalizing the One-Shot Instruction Session Using Problem-Based Learning
}

\author{
Barbara Ferrer Kenney \\ Barbara Ferrer Kenney is \\ Instructional Services Librarian at \\ Roger Williams University in Bristol, \\ Rhode Island. Submitted for review \\ December 15, 2006; accepted for \\ publication February 23, 2007.
}

Problem-based learning (PBL) provides the theoretical framework for a learner-centered active instructional experience that relies on collaboration, critical thinking, and hands-on interaction with resources. When used in a one-shot session, PBL challenges the instruction librarian to strengthen and renew their pedagogical skills. Sessions are lively and provide the opportunity for students and faculty to experience library instruction in a new and dynamic way. PBL and information literacy are ideal partners with limitless possibilities for enhanced library instruction.

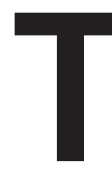

he use of Problem-based Learning (PBL) as an instructional model for teaching medical students was pioneered at McMaster University, whose Web site defines PBL as "any learning environment where the problem drives the learning." In the preface to their 1980 book, Barrows and Tamblyn, Faculty of Health Sciences at McMaster, assert that "problem-based, studentcentered learning is the most efficient method of simultaneously developing knowledge, reasoning skills, and study skills." ${ }^{2}$ Working in groups or teams of six to eight, students encounter a medical problem or case, ascertain what they already know about it, fill in information gaps by identifying and locating additional sources of information, and develop possible solutions. It is not surprising that medical librarians played an early and key role in helping both students and faculty find and evaluate sources of information for problem-solving. ${ }^{3}$ Library literature provides numerous examples of the effectiveness of using PBL in instruction sessions. Pelikan describes the library instruction module for a first-year seminar PBL class, finding that despite the additional work for the instruction librarian of designing the instruction and playing the roles of coach, presenter, and facilitator, PBL is "worth the effort" because of the similarities between the goals of PBL and information literacy instruction. ${ }^{4}$ Describing the difference between a PBL session and other instructional sessions, Cheney cites more student-instructor-librarian interaction with a clear sense of purpose on the part of the students - they knew exactly how the library session was tied to their research needs. ${ }^{5}$

The learning outcomes for PBL are congruent with the Association of College and Research Libraries (ACRL) Information Literacy Standards and include the ability to

- Think critically and be able to analyze and solve complex, real-world problems;

- Find, evaluate and use appropriate learning resources; 
- Work cooperatively in teams and small groups;

- Demonstrate versatile and effective communication skills, both verbal and written; and,

- Use content knowledge and intellectual skills acquired at the university to become continual learners. ${ }^{6}$

The process of utilizing PBL for information literacy instruction within the constraints of a fifty-minute session has been effectively described by both Macklin and Enger, while Munro discusses modifying PBL instruction from its classic form, which can prove to be beyond the capacity of a fifty-minute session. ${ }^{7}$ PBL provides the theoretical framework for a learner-centered, active instructional experience that relies on collaboration, critical thinking, and hands-on interaction with resources. Although collaboration with classroom faculty is ideal for the optimum instruction experience, it is not always possible, and PBL can be a particularly useful option for a student-centered experience designed exclusively by the librarian. When asked to provide an orientation or library tour, librarians can introduce specific resources and services within the context of the problem-solving activity. Using PBL, students become responsible for their own learning by engaging with the resources in pursuit of a solution to the problem. The tour is transformed into a user-centered activity that relies primarily on the interaction among team members, with guidance and structure provided by the librarian. While many librarians provide worksheets and exercises for an instruction session, PBL raises the instructional bar. Sessions are lively, students are engaged, and faculty are pleased with the results.

Collaborative learning is a key feature of PBL and "uses interactive applications to engage groups of learners fully by introducing real-life, or simulated, problems to be solved." ${ }^{8}$ Working together, students must strategize to solve a problem and provide evidence to support their proposed course of action. The groups are motivated because the problem is based on a classroom assignment or related to the course material. In the best of situations, the problem is designed around a course objective identified by the classroom instructor. It is in the students' self-interest to find the solution to the problem and the evidence to support the group's decision because each group will present their findings at the end of the class. The instruction librarian introduces specific resources to be searched and the student groups or teams must collaborate and mentor each other by virtue of expediency.
The librarian-facilitator introduces the problem, which students then analyze to identify what they already know about the problem and what further information they may need to find to solve it. Given the time constraints of the session, it is important to set realistic goals and outcomes and carefully design the instruction using the ACRL Information Literacy Standards. ${ }^{9}$ Using Standard One as an example, the performance indicators include defining and articulating an information need. Outcomes include conferring with instructors and participating in class discussions and peer workgroups. By definition, PBL incorporates Standard One, The information literate student determines the nature and extent of the information needed, into the learning activity. PBL takes a constructivist approach to learning, where students integrate new information into their knowledge base, as articulated as an outcome in Standard Three. Group activity is specifically identified in Standard Four, with performance indicators that correlate directly to the objectives of PBL, such as using information effectively to accomplish a specific goal.

The team members develop a strategy for solving the problem, locate the information they need within the specified resources, evaluate what they find, collaborate on the solution, and review their own performance with respect to the overall activity. How does all this happen in a fifty-minute session? By creatively designing an instruction plan that relies on defined goals and objectives based on a problem that captures student interest. PBL is a "teaching strategy that takes everyday situations and creates learning opportunities from them."10 Problems can be as simple as finding the best deal on a new car, or as sophisticated as the evaluation of a piece of legislation. Daily newspapers and reports are rich with "problem" topics.

Adding PBL to one's teaching repertoire necessitates a significant change in how we view the fifty or eighty-minute class. To use a movie metaphor, a PBL class is the trailer for the full-length feature, an experiential introduction to library research and the resources available through the library. The ultimate goal for a one-shot PBL session is to have students actively engage with the librarians and library resources to provide a glimpse into the many ways the library supports student learning. In short, the librarians are building a customer base through a skillful marketing enterprise.

An essential ingredient of a PBL session is the facilitator, a role that presents a challenge and a new mindset for many seasoned librarians. Snavely describes "revolutionizing one's own teaching style," a challenge further discussed below. ${ }^{11}$ Describing a laundry list of resources and services 
by lecturing and demonstrating is the antithesis of information literacy instruction that emphasizes user-centered, active learning and identified outcomes. The traditional role of demonstrator who provides lengthy explanations of how particular databases work and library services morphs into the role of a guide who helps focus students' problem-solving activities by shepherding them to the resources and asking pointed questions to keep them on task. In this drama, the students are the actors and the librarian is the director. To truly move from "sage on the stage to guide on the side" may prove to be the most challenging aspect of incorporating PBL into one's teaching repertoire. ${ }^{12}$

\section{DEVELOPING THE PROBLEM}

Decisions for the design of the PBL session flow from an analysis of the instruction request. From the first contact with the classroom faculty member, the librarian-instructor will decide whether the course, assignment, and instructor provide an opportunity to use PBL in that session. Considerations include whether the faculty member has requested specific materials or processes be covered; if so, can those materials be used as PBL resources. Another factor is whether the classroom instructor is providing an assignment, and if so, whether that assignment can be transformed into a learning problem. If the request is simply for a tour or orientation, PBL provides the perfect opportunity to showcase the evolution of library instruction and the value of student interaction with the resources during instruction. Having a prior relationship with the faculty member that is based on mutual respect and a common understanding of library instruction goals and student outcomes will provide the ideal environment for experimenting with PBL. If the faculty member is amenable and learning outcomes for the session are established, then a problem can be developed that captures student interest while addressing the goals of the session. Macklin provides excellent and explicit directions for creating an action plan with "specific learning goals and objectives that relate to information literacy." 13

The problem topic is best situated within the discipline, course, or assignment. Criteria for good problems include subject matter that is engaging and adaptable. "The main idea for PBL to work effectively is to write problems that require enough interaction among group members that everyone needs to be fully engaged." 14 For example, a request for a library class from a professor in Speech Communications provided me the opportunity to develop the following problem based on personal experience:

You are the senior advisor to Senator Brittany Aguilera fromNew York City. In one hour she needs to give a two-minute presentation on the Children's Internet Protection Act (CIPA) to her constituents, but she doesn't know if she's in favor of it or against it. Your job is to find reliable, authoritative information from at least five different sources. The Senator is up for re-election and your job depends upon your getting accurate information fast.

This problem was inspired by a casual conversation with a friend who is the senior advisor to a United States senator, and was a straightforward, real-world dilemma with a built-in time constraint that suited the fifty-minute time frame for the class. Situating the problem in a communications environment presented the opportunity to select resources that the students would find useful throughout the semester, as well as in other classes. Limiting the number of resources is necessary and does not compromise the effectiveness of the session. Sources for viable problems abound and can be drawn from the news, everyday life experiences, and reference tools such as CQ Researcher, which provides an excellent overview of current events and hot topics. Whether the topics are course-driven or interest-driven (for example, MySpace and privacy, global warming, immigration reform), the pedagogy is best approached using the Standards for Information Literacy developed by the Association of College and Research Libraries (ACRL). The ACRL Standards, Performance Indicators and Outcomes provide the framework for the session design. Designing problems and pedagogy that are congruent with students' academic development will keep sessions fresh and challenging. The complexity of a problem can be developed based on students' prior experience with the library as well as their academic level.

\section{DEVELOPING THE LESSON PLAN}

Designing a PLB experience is challenging and time-consuming, but it is also creative and fun. Once the problem is defined, an outline for the structure of the class is developed. It is not always necessary to have specific direction from the classroom faculty, but a pre-session conversation with the classroom faculty can be useful to ensure that the problem design flows from the course curriculum. Developing the problem enables us to draw from a world of topics to create unique, 
stimulating, and enjoyable sessions that will invite students to see us as advocates for their academic success by actively engaging with them in the learning process.

A well-structured PBL experience can be designed by asking the following five questions (the instruction goals for the "Senator Brittany Aguilera" problem are stated below the questions):

- What do you want the students to be able to do? (Outcomes)

- Use the library Web site and resources to find information

- Use specific criteria to evaluate the information found

- What does the student need to know? (Curriculum)

- The library Web site, a government Web site, a general database and evaluation criteria

- What is the learning activity? (Pedagogy)

- Short introduction to the resources

- Completion of a worksheet

- Students working in teams using predetermined resources

- Teams preselected as being either in favor of or against CIPA

- A debriefing to ascertain the teams' positions and what information sources they used to come to their decisions

- How will the students demonstrate the learning? (Assessment)

- Through their presentation and the evaluation of the resources

- Completion of a worksheet that will be graded

- How will I know the student has done this well? (Criteria)

- The students clearly articulate a viable answer to the problem with evidence from authoritative sources

\section{CHALLENGES}

Developing a timeline for the instruction session and sticking to it can prove to be a significant challenge. When designing the learning plan, it is critical to create focused chunks of time that delimit specific activities. For example, allow no more than five to ten minutes for the students to review the problem. Students will then be asked to define it clearly and concisely in accordance with Performance Indicator One of the ACRL Standards, "The information literate student defines and articulates the need for information." If students see a medical problem when what they have is a marketing problem, asking focused questions allows them to use their critical-thinking skills to clarify the nature of the problem to shape the direction of the research and solution. For example, in a case developed by a faculty collaborator, students were investigating the problem of a possible connection between high tension wires and cancer. While the students saw a medical problem, the actual problem was to develop a marketing plan for building a preschool directly under high tension wires. By asking careful questions, I was able to steer students away from the medical literature and towards newspapers and periodicals that reported the public relations issues.

For the Senator Brittany Aguilera instruction, we had an eighty-minute session, structured as follows:

- Ten minutes to review and analyze the problem

- Ten minutes to introduce the pre-determined sources and databases

- Thirty minutes to locate and evaluate the information

- Ten minutes for team consultation and decision-making

- Ten minutes for class debriefing

Keeping to a tight and controlled schedule allows for the complete unfolding of the session, with each step having significant pedagogical import. The schedule drives the collaboration and provides the class clear parameters and expectations for the session. By providing handouts that support the activity, such as evaluation criteria, and worksheets that enable students to keep a record of their results, students can stay on task and leave with the information they need for their classroom assignment.

Another challenge is changing the dynamics of the instruction session. The students will be doing the work of discovery while using the resources. The balance of the session shifts from librarian to student. Preparing for a PBL session requires librarians to ask themselves some questions about their own teaching style and pedagogy. How do we use the ACRL Standards? To what specific Standards will we be teaching? Which resources will be used and which concepts will be emphasized? What part of the research process do we want to stress? When we have only fifty or eighty minutes and everything is important, what can we possibly leave out? How comfortable are we with organized chaos? Streamlining the session applies not only to the time constraints, but also to the resources. In a PBL session, less is more. Concepts such as strat- 
egizing and evaluating may take precedence over mastering the logistics of a particular database. Teamwork is essential. Collaborative learning to promote higher-order thinking requires students to "socially negotiate learning issues inherent to the problem and defend among themselves the feasibility of those solutions." ${ }^{15}$ Almost all of the work of a PBL session is in the design and planning, and may take place weeks before the class.

Creating the teams poses another challenge. Depending on class size, teams of two or three members work best in this environment. If possible, identify students who have had previous library instruction and who are comfortable using the databases. These students are "ringers" who can be effectively peppered amongst the teams to foster peer mentoring. Providing clear guidance for a breakdown of activities for team members is helpful in structuring the activity. Suggesting that a student be assigned to the role of recorder and another to the role of presenter enables students to take responsibility in their own groups and helps facilitate the final debriefing. Nonparticipation in the activity by a team member is not an option, and it does not take long for a student to get onboard with a little help from his teammates.

Perhaps the most challenging aspect of incorporating PBL into one's teaching repertoire is taking on the role of guide, facilitator, or tutor. As the learning activity becomes user-centered, the librarian must step aside to allow the students to take responsibility for their own learning. Pelikan describes "a bias born of professional culture toward taking on the obvious role of the reference librarian, manifesting as an urge to provide solutions to the research problems faced by the teams." ${ }^{16}$ Our roles shift from providing answers in the form of information resources to asking questions that help students stay focused on the problem. Spence describes it this way: "The tutor's job is to ask provocative questions that guide further research, reduce dead-end explorations, suggest resources, provide examples, and give precise appraisals of performance." 17 This new role requires us to become comfortable with silence, spontaneity, and surprise. When introducing a problem or case, my first question is usually "what are you being asked to do?" Students become suddenly and often painfully aware that the paradigm has shifted. They are now required to carefully reread and define their problem. There may not be an immediate and enthusiastic answer, so we must learn to wait, resisting the urge to fill in the silence. It is not a role embraced by many instructors and may not suit the personality or temperament of all librarians. Once students understand that the responsibility has shifted from us to them, the stage is set for the peer mentoring that is a basic component of PBL. As the groups interact by searching the resources, sharing the information found, and evaluating it, additional questions about the relationship of the information to the problem will help navigate the students to possible solutions.

\section{REWARDS AND REFLECTIONS}

The most rewarding feature of engaging in a PBL session is having the opportunity to interact with students in a more dynamic environment. Roving among the students as they explore the resources, helping to focus their thinking, questioning their navigation strategies, and encouraging them in their choices enables them to see us as their supporters and advocates. The debriefing, which is the culmination of the session, is the most fulfilling chunk of the session. Even in the short, fifty-minute session, students establish a bond with their team members, a kind of team spirit which motivates them to find the best solution to the problem. The PBL literature discusses the "ill-structured" problem, one that has no single, perfect solution, with many information gaps. In the debriefing, acknowledging that there may be more than one solution to the problem speaks to the application of critical thinking in the PBL session. Often students identify the need for additional research themselves.

The "brass ring" of information literacy instruction is faculty collaboration. A review of the information literacy literature clearly articulates collaboration with classroom faculty as the basis for the seamless integration of information literacy into the curriculum. A satisfying outcome of a PBL session has been the opportunity to collaborate with a member of the writing faculty. While observing his students' engagement in the PBL session that I developed, this senior faculty member offered to create his own variation, a case-based problem that incorporates "the use of storytelling to engage students in the problems or dilemmas faced by the character(s) in the narrative."18 The case is the foundation for their assignment in which students must advise their employer on the better of two approaches to solving a human resource problem, either mediation or arbitration. The session took on added significance because of the relevance of the activity. In the debriefing, teams came to differing decisions, and the ensuing discussion helped students understand the need for additional research. Assessment for this class included an annotated bibliography e-mailed to and graded by the librarian instructor, with the 
grade incorporated into the course grade. While this presents the ideal situation for incorporating PBL through collaboration, it is the exception rather than the rule. The challenge to collaboration lies in the process of preparation because of "the amount of time it will take for a librarian and an instructor to come to an agreement on how to approach an assignment using PBL."19

In June 2006, at the New England Library Instruction Group's Annual Conference, Arlene Violet, former Rhode Island attorney general and local radio host, appeared as a featured panelist. She admonished librarians to "change your image," and let everyone know what we (librarians) can do for them (the faculty and public), and to better market our services and expertise. After the session, a colleague commented that many of us came to the profession so we would not have to be engaged in the business of marketing and promotion. His point is well taken in promoting the use of PBL for library instruction. While for many instruction librarians PBL presents the opportunity to re-energize one-shot sessions and experiment with a new pedagogical model, it is not an application suitable for all classes or all librarian instructors. Designing a PBL instruction class can provide the ideal opportunity to implement the ACRL Information Literacy Competency Standards. While the process may require librarians to step out of their comfort zone in the delivery of the session, it does provide the opportunity for students and faculty to experience library instruction in a new and dynamic way. The outcomes include interesting and engaging sessions with animated student engagement. Students express an interest in exploring library resources and their use for other assignments, as manifested by a significant increase in requests for research consultations at our university. One faculty collaborator has seen citations to journal articles far surpass citations to Web sites as a result of the new model. PBL has fostered and strengthened relationships with faculty and provided the opportunity to hone pedagogical skills through the planning and delivery of the sessions. PBL and information literacy are ideal partners providing interesting potential for enhanced library instruction.

\section{References}

1. Department of Chemical Engineering. "Problembased Learning Especially in the Context of Large Classes," www.chemeng.mcmaster.ca/pbl/pbl.htm (accessed June 8, 2006).
2. Howard S. Barrows and Robyn M. Tamblyn, eds., Problem-based Learning: An Approach to Medical Education (New York: Springer, 1980): xiii.

3. Janes Ohles, "Problem-based Learning: A Library Liaison's Role in Developing Life-Long Learning Skills," Medical Reference Services Quarterly 16, no. 2 (1997): 11.

4. Michael Pelikan, "Problem-based Learning in the Library: Evolving a Realistic Approach," portal: Libraries and the Academy 4, no. 4 (2004): 514.

5. Debora Cheney, "Problem-based Learning: Librarians as Collaborators and Consultants," portal: Libraries and the Academy 4, no. 4 (2004): 495.

6. Barbara J. Duch, Susan E. Groh, and Deborah E. Allen, eds., The Power of Problem-based Learning: A Practical "How To" for Teaching Undergraduate Courses in Any Discipline (Sterling, Va.: Stylus Publishing, 2001).

7. Alexius S. Macklin, "Integrating Information Literacy Using Problem-based Learning," Reference Services Review 29 no. 4 (2001): 306; Kathy B. Enger et al., "Problem-based Learning: Evolving Strategies and Conversations for Library Instruction," Reference Services Review 30, no. 4 (2002): 355; Karen Munro, "Modified Problem-based Library Instruction: A Simple, Reusable Instruction Design, College $\varepsilon$ Undergraduate Libraries 13, no. 3 (2006): 53.

8. Alexius S. Macklin, "Integrating Information Literacy Using Problem-based Learning," Reference Services Review 29 no. 4 (2001): 306.

9. Association of College and Research Libraries, "Information Literacy Competency Standards for Higher Education," www.ala.org/ala/acrl/acrlstandards/ informationliteracycompetency.cfm (accessed June 2006).

10. Macklin, "Integrating Information Literacy Using Problem-based Learning," 307.

11. Loanne Snavely, "Making Problem-based Learning Work: Institutional Challenges," portal: Libraries and the Academy, 4, no. 4 (2004): 526.

12. Allison King, "From Sage on the Stage to Guide on the Side," College Teaching 41 no. 1 (1993): 30.

13. Macklin, "Integrating Information Literacy Using Problem-based Learning," 310.

14. Ibid

15. Renée Weiss, "Designing Problems to Promote HigherOrder Thinking," Problem-based Learning in the Information Age, Dave S. Knowlton and David C. Sharp, eds. (San Francisco: Jossey-Bass, 2003).

16. Pelikan, "Problem-based Learning in the Library: Evolving a Realistic Approach," 514.

17. Larry Spence, "The Usual Doesn't Work: Why We Need Problem-based Learning," portal: Libraries and the Academy 4, no. 4 (2004): 490.

18. Linda Carder, Patricia Willingham, and David Bibb, "Case-based, Problem-based Learning: Information Literacy for the Real World," Research Strategies 18 (2001): 181.

19. Debora Cheney, "Problem-based Learning: Librarians as Collaborators and Consultants," 181. 